\title{
Neural correlates of primary and reflective consciousness of spatial orienting
}

Bartolomeo Paolo $^{1 *}$, Zieren Nikola ${ }^{2}$, Vohn René ${ }^{2}$, Dubois Bruno ${ }^{1}$, Sturm Walter ${ }^{2}$

${ }^{1}$ Neuro-anatomie fonctionnelle du comportement et de ses troubles INSERM : U610, IFR70, Université Pierre et Marie Curie - Paris VI, GH Pitie-Salpetriere 47, Boulevard de L'Hopital 75651 Paris Cedex 13,FR

2 Neurological clinic University hospital RWTH, Aachen,DE

* Correspondence should be adressed to: Paolo Bartolomeo <paolo.bartolomeo@chups.jussieu.fr>

\begin{abstract}
Using functional magnetic resonance imaging, we asked participants to perform a visual target detection task with peripheral cues. In the first part of the experiment, cues were not predictive of the side of occurrence of the incoming target. In the second part of the experiment, unbeknownst to the participants, cues became $80 \%$ predictive, thus inducing an endogenous orienting of spatial attention. Confirming previous results, in the second part response times (RTs) decreased for validly cued trials and increased for invalid trials. Half of the participants were subsequently able to correctly describe the cue-target relationships ('verbalizers'), thus demonstrating reflective consciousness of endogenous orienting. Also non-verbalizer participants showed a similar RT pattern, indicating the occurrence of endogenous orienting without reflective consciousness. Both groups of participants showed fronto-parietal activity typically observed in spatial attention tasks. Verbalizers, in addition, demonstrated stronger activity in the anterior cingulate cortex (ACC), consistent with the proposed role of this structure in purposeful behaviour and in the monitoring of its consequences. The extensive pattern of connectivity of the ACC is ideally suited to integrate the activity of the large neural assemblies necessary for reflective consciousness to emerge.
\end{abstract}

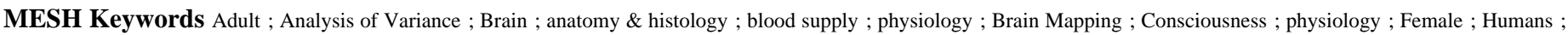

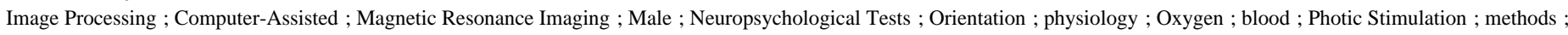
Reaction Time ; physiology ; Space Perception ; physiology ; Verbal Behavior

\section{Introduction}

Changes in brain functioning during cognitive activities may provide hints concerning the neural correlates of consciousness (see Rodriguez et al., 1999). In recent years, this idea has prompted an increasing interest for research on consciousness in cognitive neuroscience. Although it remains unclear how to establish precise causal relationships between brain events and subjective experience (Dalla Barba, 2002), patterns of neural activity which correlate in a lawful manner with the development of a determinate subjective experience can constrain models of consciousness, and may offer insights for developing rehabilitation strategies for brain-damaged patients.

The phenomenological tradition has often distinguished between primary and reflective forms of consciousness (see Bartolomeo \& Dalla Barba, 2002; Marcel, 1988; Vermersch, 2000). Primary consciousness refers to the basic condition of being aware of something. This ability is shared by humans and animals with limited semantic capabilities and no true language (Edelman \& Tononi, 2000). Humans are also capable of (presumably) higher-order forms of consciousness, which can involve linguistic abilities. In particular, reflective consciousness allows subjects to perceive and describe their own actions and thoughts. This distinction may help explaining apparently bizarre results from experimental psychology, such as the finding that people observing an array of letters for a very short time are well aware of having seen all the letters, but can name only a subset of them (Sperling, 1960). Thus, in Sperling's words, "at the time of exposure, and for a few tenths of a second thereafter, observers have two or three times as much information available as they can later report" (Sperling, 1960, p. 26). In these cases, the short presentation time may have allowed participants to develop primary, or pre-reflective consciousness of the letter identities, but may have prevented them from building more reflective forms of consciousness, necessary for accurate verbal report. In the words of Merleau-Ponty (1942), one can "live" forms of perception that one cannot speak about. Take, for example, someone who enters a room and feels an impression of disorder, only to later discover that this impression came from a crooked picture on the wall. Before discovering that, this person's consciousness was "living things that it could not spell out," and was thus a form of consciousness not immediately amenable to verbal description (Merleau-Ponty, 1942, p. 187). Also patterns of performance of brain-damaged patients, who may show a selective impairment for either variety of consciousness, may be consistent with the primary/reflective dichotomy (Bartolomeo \& Dalla Barba, 2002). For example, patients may be intellectually aware of their deficits, thus showing intact reflective consciousness, but they are often unable to compensate for them in everyday life, when more primary processes are needed. Thus, the celebrated film director F.F., who had left unilateral neglect after a right hemisphere stroke, jokingly asked to include his neglect condition in his calling card, but persisted in producing funny drawings lacking their left part (Cantagallo \& Della Sala, 1998). In a similar way, despite being anosognosic for his memory impairment, an amnesic patient was nevertheless verbally aware of his incapacity to appreciate his disorder (Dalla Barba et al., 1999). 
Cognitive neuroscientists have often focused on the study of primary consciousness, because reflective consciousness is related to meta-cognitive processes less amenable to an experimental approach (see, e.g. Crick, 1994; Edelman \& Tononi, 2000). However, if one accepts participants' verbal reports as a reliable behavioural correlate of their experiences (Merikle et al., 2001), then reflective consciousness may also be open to scientific investigation. The present study was aimed at exploring the neural correlates of a recently demonstrated dissociation between primary and reflective consciousness of orienting of spatial attention (Bartolomeo et al., 2007a; Decaix et al., 2002). Attention can be directed to an object in space either in a relatively automatic way (e.g., when a honking car attracts the attention of a pedestrian), or in a more voluntary mode (e.g., when the pedestrian monitors the traffic light waiting for the 'go' signal to appear). These two processes are often referred to as, respectively, exogenous and endogenous orienting (Posner, 1980). Exogenous orienting would be more automatic and unconscious than endogenous orienting, which is usually attributed to voluntary, strategic and conscious processes (Jonides, 1981; Posner \& Snyder, 1975). As a consequence, exogenous orienting is often unavailable to verbal report. For example, subjects may be unable to report that their attention was captured by a peripheral visual stimulus, despite response time (RT) evidence that it was (Kentridge et al., 1999; McCormick, 1997).

The voluntary nature of endogenous orienting leads to the prediction that subjects should be able to verbally report its occurrence. However, the Kentridge et al. (1999) study provided evidence that predictive properties of cues can be exploited without subsequent verbal report. In one experiment in that study, peripheral cues were used which predicted target occurrence in a remote location. Their blindsight participant learned to exploit this contingency over a few hundred trials, despite being unable to describe the occurrence of the cues or the contingency. More recently, Decaix, Siéroff, and Bartolomeo (Bartolomeo et al., 2007a; Decaix et al., 2002), used cue-target detection tasks ( Posner, 1980), in which, unbeknownst to the participants, the predictive character of the cues varied during the course of the experiment. In the first section of the experiment, cues were not predictive of the future target location (50\% "valid" trials, with targets appearing in the cued box, and 50\% "invalid" trials, with targets occurring in the uncued box). In the second section, cues could be either predictive ( $80 \%$ valid trials) or, in a different experiment, counter-predictive (20\% valid trials). Despite the fact that participants were not informed about the cue-target relationships, these influenced their RTs in the direction predicted by the development of endogenous expectations about the likely location of target occurrence. About half of the participants were subsequently able to correctly describe the cue-target relationships, and were labelled as " verbalizers'. Surprisingly, however, even the remaining participants, who were unable to produce an accurate verbal report of the task characteristics ('non-verbalizers'1), demonstrated similar validity effects, indicating analogous capacities of endogenous orienting. These results were interpreted as showing that pre-reflective forms of consciousness of the cue-target relationships need not give rise to reflective consciousness to exert their effects on performance.

In these experiments, the ability, shown by verbalizer participants, to describe the cue-target relationships was not associated with a dramatic improvement in performance as compared to non-verbalizers. This might suggest that the capacity to verbalize is a purely verbal epiphenomenon of the underlying processes, which could actually be the same in verbalizers and non-verbalizers. On the other hand, despite the lack of behavioural difference, the ability to verbalize might reflect a genuine difference in participants' subjective experience. Functional neuroimaging seems particularly apt to explore the neural correlates of participants' performance in this setting, because a single experiment with identical stimuli and procedure is used, and participants are split into two categories after having performed the experiment (see McIntosh et al., 1999). The two alternative hypotheses outlined above generate different predictions concerning the neural correlates of participants' performance.

According to the verbal epiphenomenal hypothesis (same underlying processes in the two groups, plus verbal description in verbalizers), only language-related areas of the left hemisphere might be more active in verbalizers than in non-verbalizers. If, on the other hand, the ability to verbalize reflects a specific difference in participants' subjective experience, then different brain activation patterns are expected. For example, reflective consciousness might result from a wider broadcast of information through networks of distant brain regions (see Dehaene \& Naccache, 2001; Edelman \& Tononi, 2000), than is the case for direct consciousness. If so, structures important for integrating distant neural activities, e.g. the pre-frontal regions, might be more active for verbalizer than for non-verbalizer participants.

\section{Methods}

\section{Participants}

A total of 22 undergraduates from the Aachen University (mean age 25.7 years, SD $=4.1$ years) took part in the experiments. All were right-handed and reported normal or corrected-to-normal vision. All participants were naïve to the purpose of the experiment. They gave informed consent and were paid for participation in the fMRI study. The study was approved by the local Ethics Committee of the University Hospital, Rheinisch-Westfälische Technische Hochschule, Aachen.

\section{Design and procedure}


The task stimuli were presented via a head mounted video optical unit (VisuaStim XGA with eye tracker, Arrington Research Inc.). The virtual image displayed by the unit had a maximum size of $76.2 \mathrm{~cm}$ at $1.2 \mathrm{~m}$ distance; total field of view was $30^{\circ}$. Stimulus presentation and response collection were controlled by custom-made software. Three black empty square boxes, with a 10-mm long, 0.34-mm thick side, were displayed on a white background. The boxes were horizontally arranged, the central box being located at the centre of the screen. The central box contained a small black rectangular fixation point $(1.02 \times 1.34 \mathrm{~mm})$. Distance between boxes was $30 \mathrm{~mm}$. Cues consisted of a $300-\mathrm{ms}$ thickening (from 0.34 to $0.68 \mathrm{~mm}$ ) of the contour of one box. The target was an asterisk 4.40-mm in diameter, appearing inside one of the lateral boxes, at a retinal eccentricity of about $3.83^{\circ}$.

Each trial began with the appearance of the three placeholder boxes for 1,000 ms. Then the cue followed for $300 \mathrm{~ms}$. The target appeared at a variable stimulus-onset asynchrony (SOA; 600, 800 or 1,000ms) from the cue, and remained visible for 100 ms. Multiple SOAs where used, within a range in which endogenous effects are typically observed (Müller \& Rabbitt, 1989), in order to make the cue-target interval unpredictable and hence prevent participants from responding to the time of occurrence of the target, rather than to the target itself. The different SOAs were used in a pseudorandom order. A total of $900 \mathrm{~ms}$ after target offset was allowed for response. After an intertrial interval of $1,000 \mathrm{~ms}$, a new trial began. Participants were instructed to maintain fixation on the fixation point. The experiment was stopped whenever three or more violations of the fixation instruction were detected by the eye tracker device. Fixation was trained intensively with each subject off-line; as a consequence, no participant had to be excluded during the experiment. Participants were given a nonmagnetic custom-designed cylindrically shaped response key to respond to the target stimuli with the right hand. The key was held in the closed hand and had to be squeezed for response.

There was a total of 12 runs of 12 trials each. Runs were separated by rest intervals of 18.6 sec. Following a previously described procedure (Bartolomeo et al., 2007a; Decaix et al., 2002), the cues changed their informative content during the course of the experiment, unbeknownst to participants. In the first 6 runs, targets could appear with equal probability in the cued or in the uncued box, i.e. there were equal numbers of valid and invalid trials. In the last 6 runs, $80 \%$ of trials were valid and the remaining $20 \%$ were invalid. Trials within each run were presented in a previously randomized sequence. The same sequence of trials was used for all participants. This fixed order of presentation was inevitable in order to keep possible "awareness" effects, which could only be expected under the $80 \%$-valid condition, equal across all participants.

Immediately before the experimental session, participants were orally given the following instructions: "You are going to see three boxes. Keep your gaze fixed on the central box and press this key every time you see an asterisk appear in one lateral box. Try to be as fast as possible. Before the asterisk appears, the contour of one lateral box will briefly become thicker. Do not pay attention to this occurrence and be sure to respond to the asterisk only". Soon after completion of the fMRI session, participants were asked to answer a post-experiment questionnaire (inspired by Lambert et al., 1999). The questionnaire asked whether participants noticed any cue-target relationship, and, if yes, whether cues predicted most often the target location or the wrong location (see the Appendix for an English translation). Participants were also asked to rate their confidence in their judgment on a scale ranging from 1 (pure guess) to 6 (certainly the correct choice).

\section{Magnetic Resonance Imaging}

Functional images were acquired using a Philips NT Gyroscan 1.5 Tesla scanner with a standard bird-cage head coil designed for whole-brain volume echo planar imaging (EPI). The participants were rigidly fixated in the head coil using Velcro-straps and foam padding to minimise motion artefacts. Field homogeneity was optimised for each subject before each scan using an automatic shimming sequence. Thirty-four transversal slices were acquired using a susceptibility weighted multishot T2* weighted gradient echo EPI sequence with a 3100 -ms repetition time (TR), a time to echo (TE) of 50ms and a flip angle (FA) of 90 degrees. Slice thickness was $3.4 \mathrm{~mm}$ with no interslice gap. Voxel size was $4 \times 4 \times 4 \mathrm{~mm}$. High-resolution proton density fast spin echo images $(256 \times 256$ matrix, 250×250mm FOV) were also obtained during the same scanning session to provide anatomical images for co-registration with the functional images. These anatomical scans were acquired with the following parameters: $\mathrm{TR}=204 \mathrm{~ms} ; \mathrm{TE}=14 \mathrm{~ms} ; \mathrm{FA}=90^{\circ}$. All anatomical and functional slices were obtained in transaxial planes parallel to the AC-PC line.

Functional runs consisted of 216 images, acquired in 12 alternating rest-activation pairs. In a typical box-car design 6 images were obtained in each rest epoch followed by an activation epoch of 12 images. During rest periods, participants were asked to relax but to maintain fixation (only the central fixation box was presented).

The total duration of activation and rest periods was fitted to the TR time (3100ms), duration being a multiplicator of TR time. Thus, each activation phase lasted 37.2s., each rest phase 18.6s. Total time of the experiment was $669.6 \mathrm{~s}$. The order of presentation of trials with different SOAs was pseudorandom. This provided variable TR-time intervals (jittering) across trials.

\section{Imaging Data Analysis}


The functional magnetic resonance imaging (fMRI) data were analysed using SPM2 software (Wellcome Department of Cognitive Neurology, London, UK) running under the MATLAB environment (Mathworks Inc., Sherborn, MA) (Friston et al., $1995 \mathrm{a}$; Friston et al., 1996 ; Friston et al., 1995b; Friston et al., 1994; Worsley \& Friston, 1995). All functional images were realigned to the first volume, co-registered to the anatomic images and then spatially normalized into a standardized neuroanatomical space (Talairach \& Tournoux, 1988) using the MNI (Montreal Neurological Institute, Québec, Canada) template as a reference (Ashburner \& Friston, 1999). The images were smoothed using an isotropic gaussian kernel with a FWHM of $12 \times 12 \times 12 \mathrm{~mm}^{3}$.

The functional data were analysed using the General Linear Model implemented in SPM2. Data of the 22 participants were averaged in a group analysis using the random effects model approach (second level analysis; Friston et al., 1999). Statistical parametric maps (SPMs) were obtained and voxels were considered significant if their corresponding linear contrast t-values (compared to the rest periods) were significant at a level of $\mathrm{p} \leq 0.001$ (uncorrected, cluster size $\mathrm{k}=5$ voxels).

Additionally, for a comparison of the two subgroups differing with respect to awareness (see results section) two-sample t-tests were calculated both for the $80 \%$ and for the $80 \%$ minus $50 \%$ conditions, in order to compare the significant activations of the contrasts mentioned above between these two groups. Finally, a conjunction analysis was done for the $80 \%$ condition in order to reveal possible overlaps of activation patterns for the two groups. In order to take into account the lower statistical power of two-sample t-tests, for these analyses an uncorrected $\mathrm{p} \leq 0.01$ was used.

\section{Results}

\section{Behavioural results}

The initial runs for each level of cue predictiveness (runs 1 and 7) were considered as practice and discarded from further analysis. The mean RT and SD were calculated for each participant, and RTs exceeding the range of 2.5 SDs around the participant's mean were considered as outliers and discarded from further analysis. The trimming procedure resulted in the exclusion of less than $2 \%$ of responses. Mean RTs were entered in a repeated-measures analysis of variance (ANOVA), with group (verbalizers, non-verbalizers) as between-participants factor and section (first, 50\% valid cues; second, 80\% valid cues), cue (valid, invalid) and SOA (600, 800, 1,000 ms) as within-participants factors.

Based on the results of the post-experiment questionnaire, participants were divided into two groups, which happened to be of equal size: those who responded correctly to the questionnaire, hereafter the verbalizer group $(\mathrm{N}=11)$, and those who gave inaccurate responses, the non-verbalizer group $(\mathrm{N}=11)$. Specifically, participants were characterized as verbalizers when they correctly described the cue-target relationship in question (2) (see Appendix), ticked "possibly correct" or more in question (3), and chose the correct alternative in question (4). Question (5) was not taken into account because only few of the verbalizers could correctly classify the time. Interestingly, very similar figures (7 verbalizers and 9 non-verbalizers) were obtained in a previous similar experiment, which employed a similar procedure with different participants and fewer trials in section 1 than in section 2 (Bartolomeo et al., 2007a; Decaix et al., 2002, Experiment 1). The two groups had exactly the same mean confidence rating, 4.00 (range, 3-6). Thus, no participant rated his or her response as resulting from pure guess.

Behavioural responses were successfully recorded from 17 of 22 participants during fMRI data acquisition (for 4 verbalizers and 1 non-verbalizer some of the recordings were erroneous and thus their behavioural data had to be excluded from analysis; the fMRI results for these participants were, however, used in the fMRI analysis). Table 1 reports the results for the two groups. The effect of group did not reach significance, $\mathrm{F}(1,15)=2.52, \mathrm{p}=0.13$. The tendency was toward verbalizers being $41 \mathrm{~ms}$ faster than non-verbalizers. Overall, valid trials evoked responses $18 \mathrm{~ms}$ slower than invalid trials, $\mathrm{F}(1,15)=7.52, \mathrm{p}=0.02$. There was an effect of SOA, F $(2,30)=26.70, \mathrm{p}<0.001$, because RTs tended to speed up with increasing SOAs. Importantly, an interaction between condition and cue validity emerged, $\mathrm{F}(1,15)=20.36, \mathrm{p}=$ 0.0004 .

In the section with non-informative, $50 \%$ valid cues, RTs were faster for invalid trials $(301 \mathrm{~ms})$ than for valid trials (329ms), consistent with a typical 28-ms inhibition of return (IOR; see Lupiáñez et al., 2006; Posner \& Cohen, 1984). In the 80\% validity section, instead, valid trials evoked similar RTs $(321 \mathrm{~ms})$ as invalid trials $(312 \mathrm{~ms})$, as if an endogenous facilitation for validly cued targets offset IOR (Lupiáñez et al., 2004 ). No other effect or interaction reached significance2.

Planned comparisons showed that the section by validity interaction was statistically reliable both for verbalizers, $\mathrm{F}(1,15)=11.68, \mathrm{p}=$ 0.004 , and for non-verbalizers, $\mathrm{F}(1,15)=8.69, \mathrm{p}=0.01$ (Fig. 1). Thus, participants unable to verbally report about the correct relationships between cues and targets were nevertheless able to employ these relationships to speed up their responses to validly cued targets in section 2 . This pattern of results closely replicates the findings of the previous behavioural studies employing a similar paradigm (Bartolomeo et al., 2007a; Decaix et al., 2002), and suggests that endogenous orienting processes may be unavailable to reflective consciousness and, consequently, to verbal report. The alternative possibility, namely a decrease of IOR from the first to the second section resulting from practice 
(see Weaver et al., 1998), is highly unlikely, because practice-related reductions of IOR in detection tasks typically only occur after 200 or more trials (Lupiáñez et al., 2001). Moreover, this possibility was directly excluded by Bartolomeo et al. (2007a, Exp. 2), who found unchanging IOR in an experiment similar to the present one, but with equal proportions of valid and invalid trials in both sections of the experiment.

Despite the similar performance of verbalizers and non-verbalizers on both sections of the experiment, there might be differences in the timing of the use of endogenous strategies in the two groups. For example, verbalizers might have employed the correct strategy earlier in the course of the second section than non-verbalizers. To check for this possibility, we split the data points of each section in an early period and a late period ( $\mathrm{N}=36$ trials each). A further ANOVA was performed with group (verbalizers, non-verbalizers) as between-participants factor and section (first, 50\% valid cues; second, $80 \%$ valid cues), cue (valid, invalid) and period (early, late) as within-participants factors3. Once again, the group factor did not interact with any other factors (all Fs $<1$ ), inconsistent with the timing hypothesis. An unexpected interaction emerged between section, period and validity, $\mathrm{F}(1,14)=7.49, \mathrm{p}=0.02$, because in the early period of the second section there was a small but positive advantage for cued trials, which became a cost in the late period. However, the amount of the small cue validity effect in the early period of the $80 \%$ valid section was not larger for verbalizers ( $4 \mathrm{~ms})$ than it was for non-verbalizers $(8 \mathrm{~ms})$.

\section{Imaging results}

Participants tended to show much stronger activations in the first section of the experiment (50\% valid condition) compared to the second section ( $80 \%$ valid condition), which rendered any direct comparison between the conditions difficult. This effect could either result from practice decreasing the BOLD signal (Kelly \& Garavan, 2005), or from some intrinsic difference between the two conditions. To adjudicate between these possibilities, three additional participants were tested with a similar procedure, except that the order of the sections was reversed; the experiment now started with the $80 \%$ valid condition and ended with the $50 \%$ condition. The additional participants again demonstrated stronger activation in the first half of the experiment compared to the second one, thus corroborating the practice hypothesis $(\mathrm{p}=0.001$, fixed effects analysis for complex contrasts $50 \%-80 \%$ vs. $80-\%-50 \%$ across 3 subjects). The results (Fig. 2) showed an overall stronger activations when the $50 \%$-condition was subtracted from the $80 \%$ condition (Fig. 2a) than for the subtraction the other way round (80-50\%, Fig. 2b).

To investigate the possible differences in brain activation between verbalizers and non-verbalizers, the participants were split according to the answers given to the post-experiment questionnaire, following the method used for the behavioural analysis; a second-level-analysis was done across all participants of each group for the $80 \%$ valid condition, which is specifically related to endogenous orienting processes ( $\mathrm{p} \leq$ $0.001)$.

In order to compare the significant activations of the contrasts mentioned above between the two awareness groups, a two-sample t-test was calculated both for the $80 \%$ and for the $80 \%$ minus $50 \%$ conditions. Finally, a conjunction analysis was done for the $80 \%$ condition in order to reveal possible overlaps of activation patterns for the two groups. For each of these analyses an uncorrected $\mathrm{p} \leq 0.01$ was chosen.

\section{Verbalizers}

Verbalizers showed bilateral activation in the inferior parietal lobule and right hemisphere (RH) activation in the superior parietal lobule, as well as activation in the precuneus of the left hemisphere (LH) (Table 2 and Fig. 3a). In the frontal cortex, there was mostly RH activation in the precentral and medial frontal cortex and in the rostral part of the anterior cingulate gyrus (see Picard \& Strick, 1996). Besides a right inferior temporal gyrus and fusiform gyrus activation, there were foci in left subcortical areas (thalamus, putamen and caudate nucleus).

\section{Non-verbalizers}

Non-verbalizers revealed parietal activation in the right superior parietal lobule as well as a LH focus in the postcentral gyrus (Table 3, Fig. 3b). In the frontal cortex, there were bilateral activations in the superior and middle frontal gyrus, as well as a left cingulate gyrus activation. Furthermore, there was a right middle temporal and fusiform gyrus activation and a focus in the right caudate.

\section{Verbalizers vs. non-verbalizers}

Two sample t-tests were conducted to compare the activations of verbalizer and non-verbalizer participants within the different conditions ( $80 \%$ and $80-50 \%$ conditions). Brain areas showing significant increases of activation are presented below, listing all cortical regions comprising at least 5 voxels.

Verbalizers > non-verbalizers, $80 \%$ valid condition 
When compared to non-verbalizers, verbalizers showed stronger activation in the left superior parietal lobule, bilaterally in the rostral anterior cingulate cortex (ACC), middle temporal gyrus and fusiform gyrus, in the left inferior frontal and right precentral gyrus and in the left amygdala (Fig. 3c, Table 4). The global maximum of the ACC activation was very close to the corpus callosum but the nearest grey matter activation was clearly referred to the ACC. An anatomical view of the right ACC activation is depicted in fig. $3 \mathrm{f}$.

\section{Non-verbalizers > verbalizers, $80 \%$ valid condition}

Non-verbalizers compared to verbalizers revealed stronger activation only in bilateral inferior frontal gyri (Fig. 3d, Table 5).

\section{Conjunction analysis, verbalizers and non-verbalizers, $80 \%$ valid condition}

A conjunction analysis was done for the $80 \%$ condition in order to reveal possible overlaps of activation patterns for the two groups. There was significant overlap in the right inferior parietal lobule, bilaterally in the middle frontal gyrus, in the right inferior and left superior frontal gyrus and in the right superior temporal gyrus (Fig. 3e, Table 6).

\section{Verbalizers > non-verbalizers, $80 \%-50 \%$ valid conditions}

In these complex contrasts, the $50 \%$ valid condition is subtracted from the $80 \%$ condition, so that only those activations reach significance that are activated in the $80 \%$ and not in the $50 \%$ condition. Thus, these contrasts only show the areas specific to the $80 \%$ valid condition.

Under this condition, verbalizers compared to non-verbalizers showed a significantly stronger activation in the right rostral section of the anterior cingulate gyrus, the left superior and inferior parietal lobules, the right brain stem and the right fusiform gyrus ( $\mathrm{p}=0.01$, uncorrected, see Fig. $4 \mathrm{a}$ and Table 7). An anatomical view of the right ACC activation under the $80 \%$ minus $50 \%$ condition is presented in fig. $4 \mathrm{c}$.

\section{Non-verbalizers > verbalizers, $80 \%-50 \%$ valid conditions}

Non-verbalizers compared to verbalizers revealed significantly stronger activations in the right inferior frontal gyrus and in the right inferior parietal lobe but also (if less prominent) in the right middle and superior frontal and in the right inferior temporal gyrus ( $\mathrm{p}=0.01$, uncorrected, see Fig. $4 \mathrm{~b}$ and Table 8).

\section{Discussion}

Cue-target RT paradigms are widely used to explore the orienting of spatial attention and its disorders (Posner, 1980). Functional MRI studies using various implementations of these paradigms have demonstrated the activation of large distributed fronto-parietal networks ( Corbetta \& Shulman, 2002; Nobre, 2001; Rosen et al., 1999). The present study took a different approach, in which a cued detection task was used to explore different forms of awareness of the cue-target relationships, as assessed by a post-experiment questionnaire.

The current behavioural results closely replicate previous findings (Bartolomeo et al., 2007a; Decaix et al., 2002), showing that when spatial cues change their informative value during the experiment, and become useful to predict the side of occurrence of the incoming targets, participants are able to adopt strategies of endogenous orienting of spatial attention. Importantly, we replicated the previous finding that endogenous orienting can occur independent of participants' ability to subsequently describe their strategy. Only half of the participants were able to do so; however, there was no major difference in their RT pattern of results, consisting in an IOR pattern in the $50 \%$ valid condition, followed by longer RTs to invalidly cued targets and shorter RTs to validly cued ones in the $80 \%$ valid condition. Thus, both in the previous and in the present study, not only could participants who failed to report the changed contingency verbally nevertheless make use of the changed contingency, but their behaviour (as expressed in terms of cue effects on RTs) did not differ from that of the explicitly verbalising participants -- they were not less effective than the verbalizers at using the changed contingency. Again consistent with the previous experiments, in the $80 \%$ valid condition valid cues did not produce faster RTs than invalid ones because valid peripheral cues, appearing, as they do, in the same location of subsequent targets, induce IOR -- in other words a cost in responding to stimuli at a recently attended location ( Berlucchi et al., 2000; Lupiáñez et al., 2004). Thus, IOR may cancel the effects of endogenous facilitation on RTs (Berlucchi et al., 2000; Lupi áñez et al., 2004).

The imaging results for the $80 \%$ condition (see Fig. 3) replicated the findings of previous neuroimaging studies demonstrating the implication of large fronto-parietal networks in orienting of spatial attention (Corbetta \& Shulman, 2002; Nobre, 2001; Rosen et al., 1999) (see also Bartolomeo et al., 2007b; Doricchi \& Tomaiuolo, 2003; Mesulam, 1999; Thiebaut de Schotten et al., 2005, for further supporting evidence from brain-damaged patients). When activity relative to the $50 \%$ condition was subtracted out, non-verbalizers compared to verbalizers 
continued to show fronto-parietal activity, particularly in right inferior frontal and inferior parietal regions (see Fig. 4b), corresponding to the ventral fronto-parietal network described by Corbetta and Shulman (2002), as important for responding to unexpected targets. This may suggest that non-verbalizers' pre-reflective endogenous expectancies concerning the side of occurrence of the target in the $80 \%$ valid condition were somewhat less consistent than those developed by verbalizers. Non-verbalizers may have failed to expect the correct location of a larger number of targets as compared to verbalizers, with corresponding more frequent activation of the ventral attentional network.

But what are the neural correlates of the ability to verbally report one's orienting strategy? Verbalizer participants, in comparison with non-verbalizers, showed stronger activations in the anterior cingulate cortex (ACC) and in the superior parietal lobe as well as in the superior part of the brain stem (see Fig. 3c and table 7). The most strict (while most conservative) result is the activation under the 80-50\% condition, because differences in activations which might arise between verbalizers and nonverbalizers at the beginning of the experiment under the nonpredictive $50 \%$ condition are subtracted out. Both the pure $80 \%$ and the $80-50 \%$ condition, however, led to quite comparable results regarding the ACC. Although the coordinates differed slightly $(x=12, y=17, z=21$ vs. $x=20, y=36, z=17)$, the activation foci both lie within the right rostral section of the ACC, as defined by Picard and Strick (1996) 4.

This result is not consistent with the hypothesis that the ability to verbalize is merely epiphenomenal, which would have predicted activations in language-related areas (although the parietal activations in verbalizers are mainly in the left hemisphere, see Fig. 4a and table 7). It suggests, instead, that verbalizers were able to describe the cue-target relationships because they had actively formulated hypotheses about these relationships during the second half of the experiment. A straightforward interpretation of the ACC activation in verbalizers may rest on the well-known role of this structure in cognitive control. Many studies have addressed the ACC as a centre for anticipation and preparation of attentional activity (LaBerge \& Buchsbaum, 1990; Murtha et al., 1996; Paus, 2001) but also for preparation of motor action (for a review and reinterpretation of ACC sections see Picard \& Strick, 1996). ACC activity typically correlates with tasks requiring a voluntary action and the monitoring of its consequences (Walton et al., 2004). In a PET study, Paus et al. (1993) found an activation focus within 15mm of the focus described here when participants endogenously generated saccades in response to central cues, after reversal of the previously overpracticed cue-target contingencies $(x=7, y=27, z=29$ in the reversal minus overpractice subtraction). A nearby focus was activated when participants had to produce saccades away from a visual stimulus $(x=1, y=10, z=42$ in the antisaccade minus prosaccade subtraction). In these two conditions, participants had to exert an endogenous control over their spatial orienting by actively contrasting automatic tendencies. Also evidence from patients with ACC lesions, who typically show abulia and lack of spontaneous activity (Laplane et al., 1981), is consistent with these proposals. Carter et al. (1999) argued that the ACC is involved in executive processes and that it serves an evaluative function in executive control, rather than a strictly strategic function. A recent fMRI study with the attention network test (Fan et al., 2002) found ACC activation for the executive part of the task (Fan et al., 2005).

Many studies revealed an involvement of the ACC in response conflict [e.g. in the Stroop task (Carter et al., 1995; Pardo et al., 1990), or in verb generation (Barch et al., 2000)]. Although some of these studies demonstrated right rostral ACC activations, they seemed more medial (x $=2$ or 3 ) than our activations $(\mathrm{x}=12$ or 20$)$. A similar consideration applies to the medial frontal activations related to erroneous responses ( Hester et al., 2005, $x=3, y=40, z=20$; Klein et al., 2007, $x=-2, y=30, z=27$ ). More importantly, although error awareness might well be considered as a special case of reflective consciousness, in both these studies error-related medial frontal activations were apparently unmodulated by error awareness, being present for both aware and unaware errors. Important methodological differences preclude a direct comparisons between these studies and ours; nevertheless, this discrepancy recommends prudence in interpreting our results merely in terms of error awareness.

More relevant to the present RT task, an important role of the ACC seems to be the modulation of arousal depending on task demands ( Mottaghy et al., 2006; Sturm et al., 1999; Sturm et al., 2004). In the present experiment, such an up-regulation of arousal seems to be behaviourally reflected by the nonsignificant tendency shown by verbalizer participants to respond faster than non-verbalizers, which was paralleled by an activation of the brain stem as a part of the arousal/alerting system. The role of the ACC in the control of arousal was further underlined by a review of PET studies focusing on this structure (Paus et al., 1998). The authors found that task difficulty was strongly correlated with activation peaks especially in the supracallosal part of the ACC, more difficult tasks possibly calling for an increased level of arousal and a higher activation of the brain stem catecholaminergic systems. The ACC cortical region is densely connected to the noradrenergic (Gaspar et al., 1989) and cholinergic (Mesulam et al., 1992) subcortical systems involved in the regulation of arousal (see also Sarter et al., 2001).

Visual awareness is often considered to correlate with fronto-parietal activity (Rees et al., 2002). Stephan et al. (2003) showed enhanced coupling of the right ACC during visuospatial decisions. The present results are not inconsistent with these findings, because all participants were presumably well aware of the occurrence of cues and targets, independent of their capacity to subsequently describe the cue-target contingencies. This is reflected by the fact that both verbalizers and nonverbalizers showed fronto-parietal activation (see conjunction analysis, 
table 6 and Fig. 3e), but only the verbalizers revealed stronger mostly right rostral ACC activity. One might surmise that ACC activation in verbalizers was a consequence of their being aware of the cue-target relationship, which in turn prompted them to control their behaviour (i.e., to explicitly expect the target at the cued location). According to this view, the right rostral ACC activation would be the neural correlate of this control. Alternatively, the "awareness" of the cue-target relationships could be nothing over and above the willed control of action. Monitoring systems might employ the same neural resources that are responsible for the primary function that has to be monitored (see Berti et al., 2005). Cognitive processing is increasingly seen as a set of active processes, rather than passive representation of information. In particular, consciousness, like locomotion, might be more related to intrinsic neural activity than to sensory representations (Llinas et al., 1998). According to another similar proposal, experience is something the animal "enacts" as it explores its environment (see also O'Regan \& Noë, 2001; Varela et al., 1991). If so, the right rostral ACC activation might constitute the direct neural correlate of participants' reflective consciousness.

The ACC, with its wide-ranging cortical and subcortical connectivity, seems ideally suited to integrate the activity of different neural assemblies, situated in brain regions far from one another. This integration is likely to be a necessary condition for consciousness to emerge ( Dehaene \& Naccache, 2001; Edelman \& Tononi, 2000). Reflective consciousness, indispensable to accurate verbal report, might require an even broader long-distance integration than primary consciousness, and may thus well correlate with a comparatively higher activity of ACC, consistent with the present results.

A crucial question for future research concerns the specific conditions under which information gains access to the ACC for wide neural broadcasting and consequent explicit knowledge. Further questions are related to the potential of communication between these different forms of consciousness and to the possibilities to influence it. It could be important, for example, to render pre-reflective forms of consciousness more explicit, in order to enhance learning abilities. On the other hand, the availability of reflective forms of consciousness for use in everyday life could help rehabilitation of neuropsychological deficits, of which patients may be reflectively, but not directly aware (Bartolomeo \& Dalla Barba, 2002).

To conclude, we note that research on the cognitive neuroscience of consciousness faces peculiar problems (Petitot et al., 1999). In extreme synthesis, how can a (third-person) scientific enterprise tell something about first-person experience (Nagel, 1974)? According to Owen Flanagan (2000), the scientific methods can be applied to the study of consciousness by using converging evidence coming from (1) experimental psychology, (2) phenomenology (as inferred by participants' reports of their experiences) and (3) neuroscience. We believe that the present study, which combined these three sources of evidence in the form of manual response times, verbal reports and fMRI, provides a concrete, if preliminary, example of such an integrated research approach.

\section{Footnotes:}

We prefer these descriptive labels to the less theoretically neutral "aware/unaware", which would imply a total lack of awareness for participants unable to provide an accurate verbal description. See Bartolomeo et al. (2007a) for further discussion.

2

In particular, the group $\mathrm{x}$ section $\mathrm{x}$ validity interaction did not approach significance, $\mathrm{F}<1$. This suggests that the effect of endogenous attention in section 2 was not larger in verbalizers than in non-verbalizers.

3

We thank an anonymous reviewer for suggesting this analysis. RTs for the 3 SOAs were pooled together in order to obtain a sufficient number of data points.

4

According to other classifications (e.g., Vogt et al., 2003), these ACC foci might have different cytoarchitecture and functions. The level of resolution and statistical power of the present contrasts are probably insufficient to settle the issue.

\section{References:}

- Ashburner J , Friston KJ 1999; Nonlinear spatial normalization using basis functions. Human Brain Mapping. 7: (4) $254-266$

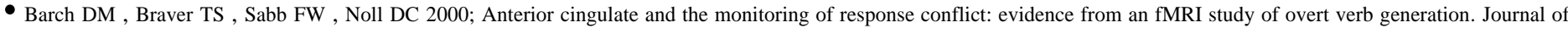
Cognitive Neuroscience. 12: (2) 298- 309

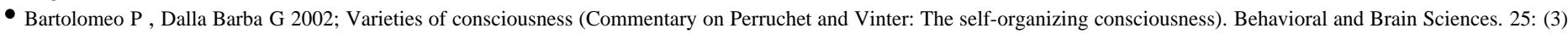
331- 332

- Bartolomeo P , Decaix C , Siéroff E 2007a; The phenomenology of endogenous orienting. Consciousness and Cognition. 16: (1) 144- 161 
- Bartolomeo P, Thiebaut de Schotten M , Doricchi F 2007b; Left unilateral neglect as a disconnection syndrome. Cerebral Cortex. 10.1093/cercor/bhl1181

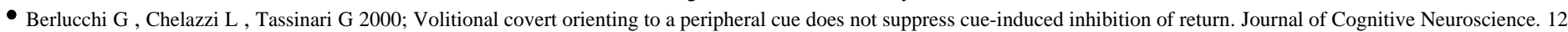
: (4) 648- 663

- Berti A , Bottini G, Gandola M , Pia L, Smania N , Stracciari A 2005; Shared cortical anatomy for motor awareness and motor control. Science. 309: (5733) 488- 491

- Cantagallo A, Della Sala S 1998; Preserved insight in an artist with extrapersonal spatial neglect. Cortex. 34: (2) 163- 189

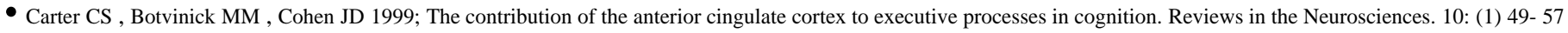

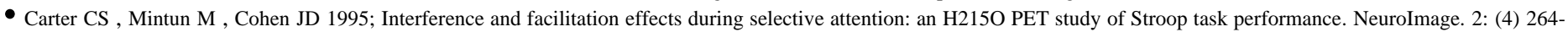
272

- Corbetta M , Shulman GL 2002; Control of goal-directed and stimulus-driven attention in the brain. Nature Reviews Neuroscience. 3: (3) 201- 215

- Crick F 1994; The astonishing hypothesis: the scientific search for the soul. New York Scribner;

- Dalla Barba G 2002; Memory, Consciousness and Temporality. Boston Kluver Academic Publishers;

- Dalla Barba G, Bartolomeo P , Ergis AM , Boissé MF , Bachoud-Lévi AC 1999; Awareness of anosognosia following head trauma. Neurocase. 5: (1) 59- 67

- Decaix C, Siéroff E, Bartolomeo P 2002; How voluntary is 'voluntary' orienting of attention?. Cortex. 38: (5) 841- 845

- Dehaene S, Naccache L 2001; Towards a cognitive neuroscience of consciousness: basic evidence and a workspace framework. Cognition. 79: (1-2) 1- 37

- Doricchi F , Tomaiuolo F 2003; The anatomy of neglect without hemianopia: a key role for parietal-frontal disconnection?. NeuroReport. 14: (17) 2239- 2243

- Edelman GM , Tononi G 2000; A universe of consciousness: how matter becomes imagination. New York, NY Basic Books;

- Fan J, McCandliss BD , Fossella J , Flombaum JI , Posner MI 2005; The activation of attentional networks. NeuroImage. 26: (2) 471 - 479

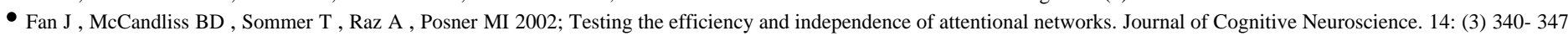

- Flanagan OJ 2000; Dreaming souls: sleep, dreams, and the evolution of the conscious mind. Oxford; New York Oxford University Press;

- Friston KJ , Frith CD , Turner R, Frackowiak RS 1995a; Characterizing evoked hemodynamics with fMRI. Neuroimage. 2: (2) 157- 165

- Friston KJ , Holmes A , Poline JB , Price CJ , Frith CD 1996; Detecting activations in PET and fMRI: levels of inference and power. Neuroimage. 4: (3 Pt 1) 223- 235

- Friston KJ , Holmes AP , Poline JB , Grasby PJ , Williams SC , Frackowiak RS 1995b; Analysis of fMRI time-series revisited. Neuroimage. 2: (1) 45- 53

- Friston KJ , Holmes AP , Worsley KJ 1999; How many subjects constitute a study?. Neuroimage. 10: (1) 1- 5

- Friston KJ , Jezzard P , Turner R 1994; Analysis of functional MRI time-series. Human Brain Mapping. 1: (2) $153-171$

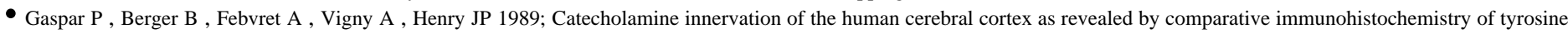
hydroxylase and dopamine-beta-hydroxylase. Journal of Comparative Neurology. 279: (2) 249- 271

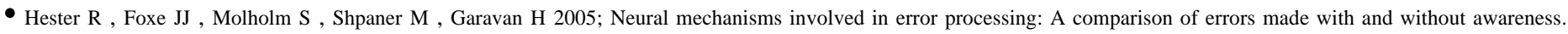
NeuroImage. 27: (3) 602- 608

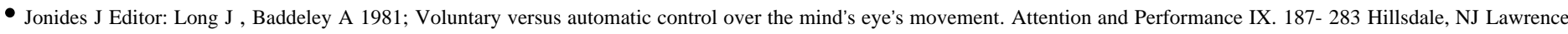
Erlbaum;

- Kelly AMC, Garavan H 2005; Human functional neuroimaging of brain changes associated with practice. Cerebral Cortex. 15: (8) 1089- 1102

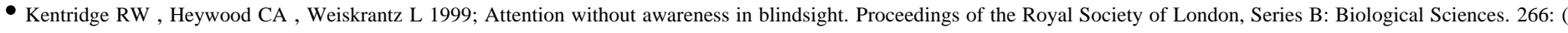
1430) 1805- 1811

- Klein TA, Endrass T, Kathmann N, Neumann J , von Cramon DY, Ullsperger M 2007; Neural correlates of error awareness. NeuroImage. 34: (4) 1774- 1781

- LaBerge D , Buchsbaum MS 1990; Positron emission tomographic measurements of pulvinar activity during an attention task. Journal of Neuroscience. 10: (2) 613- 619

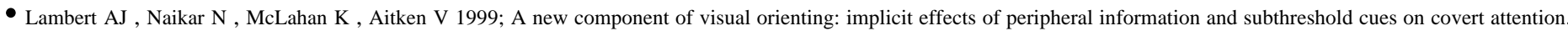
Journal of Experimental Psychology: Human Perception and Performance. 25: (2) 321- 340

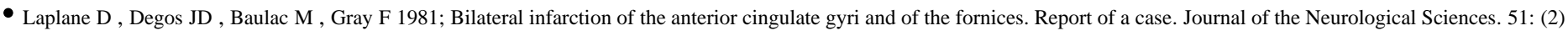
289- 300

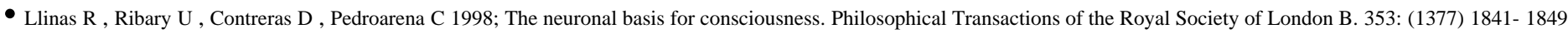

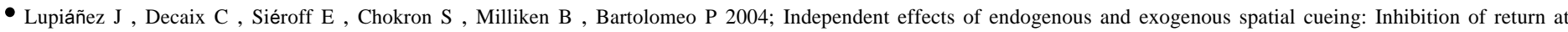
endogenously attended target locations. Experimental Brain Research. 159: (4) 447- 457

- Lupiáñez J , Klein RM , Bartolomeo P 2006; Inhibition of return: Twenty years after. Cognitive Neuropsychology. 23: (7) 1003- 1014

- Lupiáñez J , Weaver B , Tipper SP , Madrid E 2001; The effects of practice on cueing in detection and discrimination tasks. Psicológica. 22: (1) 1- 23

- Marcel AJ Editor: Marcel AJ , Bisiach E 1988; Phenomenal experience and functionalism. Consciousness in contemporary science. 121- 158 Oxford Oxford University Press;

- McCormick PA 1997; Orienting attention without awareness. Journal of Experimental Psychology: Human Perception and Performance. 23: (1) 168- 180

- McIntosh AR, Rajah MN , Lobaugh NJ 1999; Interactions of prefrontal cortex in relation to awareness in sensory learning. Science. 284: (5419) 1531- 1533

- Merikle PM , Smilek D , Eastwood JD 2001; Perception without awareness: perspectives from cognitive psychology. Cognition. 79: (1-2) 115- 134

- Merleau-Ponty M 1942; La structure du comportement. Paris Presses Universitaires de France;

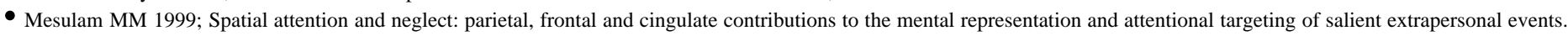
Philosophical Transactions of the Royal Society of London B. 354: (1387) 1325- 1346

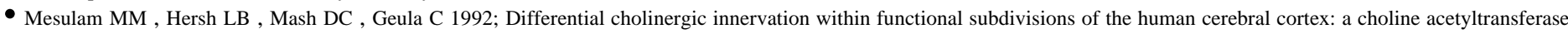
study. Journal of Comparative Neurology. 318: (3) 316- 328

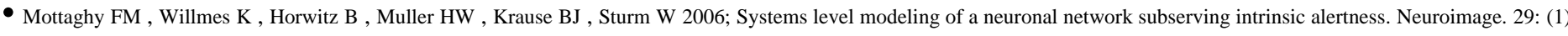
225- 233

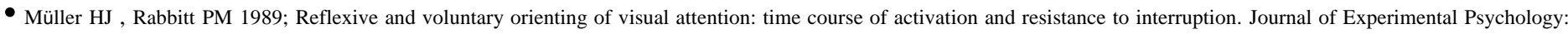
Human Perception and Performance. 15: (2) 315- 330

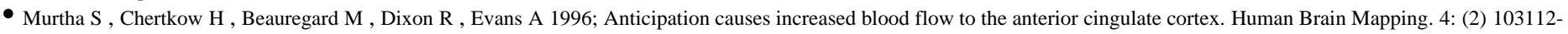

- Nagel T 1974; What is it like to be a bat?. Philosophical Review. 83: 435- 456

- Nobre AC 2001; The attentive homunculus: now you see it, now you don't. Neuroscience and Biobehavioral Reviews. 25: (6) 477- 496

- O'Regan JK , Noë A 2001; A sensorimotor account of vision and visual consciousness. Behavioral and Brain Sciences. 24: (5) 939- 1011

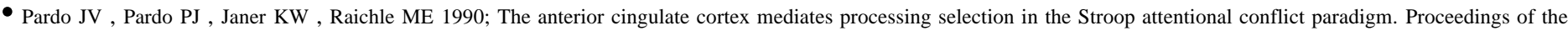
National Academy of Sciences of the United States of America. 87: (1) 256- 259

- Paus T 2001; Primate anterior cingulate cortex: where motor control, drive and cognition interface. Nature Reviews Neuroscience. 2: (6) 417- 424

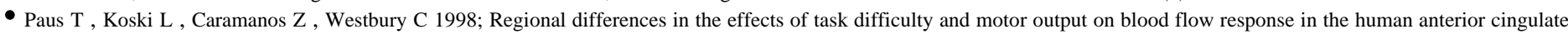
cortex: a review of 107 PET activation studies. NeuroReport. 9: (9) R37- 47

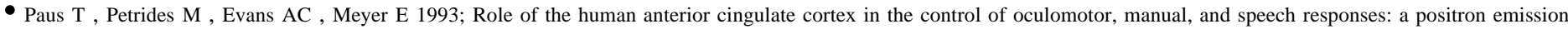
tomography study. Journal of Neurophysiology. 70: (2) 453- 469

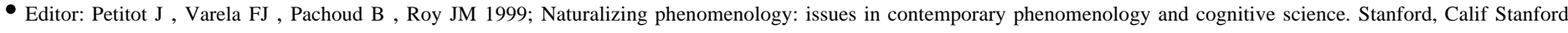
University Press;

- Picard N, Strick PL 1996; Motor areas of the medial wall: a review of their location and functional activation. Cerebral Cortex. 6: (3) 342- 353 
- Posner MI 1980; Orienting of attention. The Quarterly Journal of Experimental Psychology. 32: 3- 25

- Posner MI , Cohen Y Editor: Bouma H , Bouwhuis D 1984; Components of visual orienting. Attention and Performance X. 531- 556 London Lawrence Erlbaum;

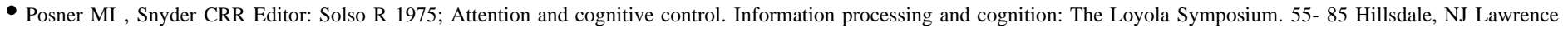
Erlbaum;

- Rees G , Kreiman G , Koch C 2002; Neural correlates of consciousness in humans. Nature Reviews Neuroscience. 3: (4) 261- 270

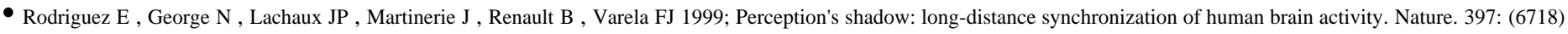
430- 433

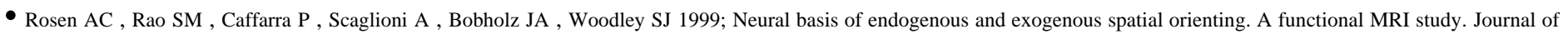
Cognitive Neuroscience. 11: (2) 135- 152

- Sarter M , Givens B , Bruno JP 2001; The cognitive neuroscience of sustained attention: where top-down meets bottom-up. Behavioral Brain Research. 35: (2) 146- 160

- Sperling G 1960; The information available in brief visual presentations. Psychological Monographs: General and Applied. 74: (11, Whole No. 498) 1- 29

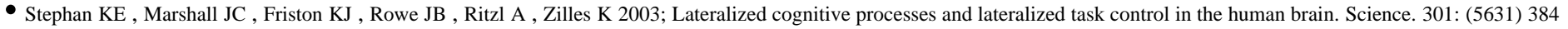
$-386$

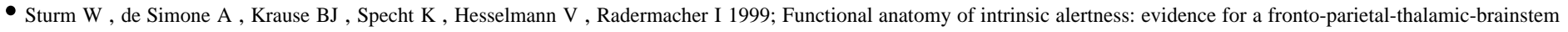
network in the right hemisphere. Neuropsychologia. 37: (7) 797- 805

- Sturm W, Longoni F , Fimm B , Dietrich T, Weis S, Kemna S 2004; Network for auditory intrinsic alertness: a PET study. Neuropsychologia. 42: (5) 563- 538

- Talairach J , Tournoux P 1988; Co-planar stereotaxic atlas of the human brain: an approach to medical cerebral imaging. Stuttgart; New York Thieme Medical Publishers;

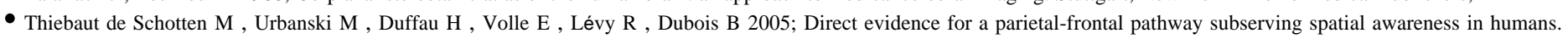
Science. 309: (5744) 2226- 2228

- Varela FJ , Thompson E, Rosch E 1991; The embodied mind: cognitive science and human experience. Cambridge, Mass MIT Press;

- Vermersch P 2000; Conscience directe et conscience réfléchie [Direct consciousness and reflexive consciousness]. Intellectica. 31: (2) 269- 311

- Vogt BA, Berger GR , Derbyshire SW 2003; Structural and functional dichotomy of human midcingulate cortex. European Journal of Neuroscience. 18: (11) 3134- 3144

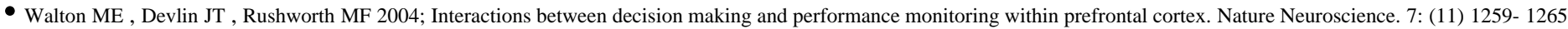

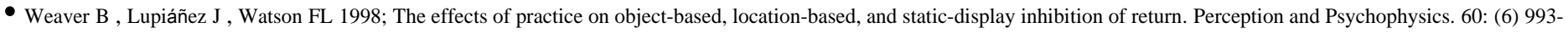
1003

- Worsley KJ , Friston KJ 1995; Analysis of fMRI time-series revisited--again. Neuroimage. 2: (3) 173- 181

Fig. 1

Response Times (in ms) for verbalizer and non-verbalizer participants as a function of the percentage of valid trials in the two consecutive parts (section 1: 50\% valid cues; section 2: $80 \%$ valid cues)

SECTION 1: $50 \%$ valid cues; SECTION 2: $80 \%$ valid cues
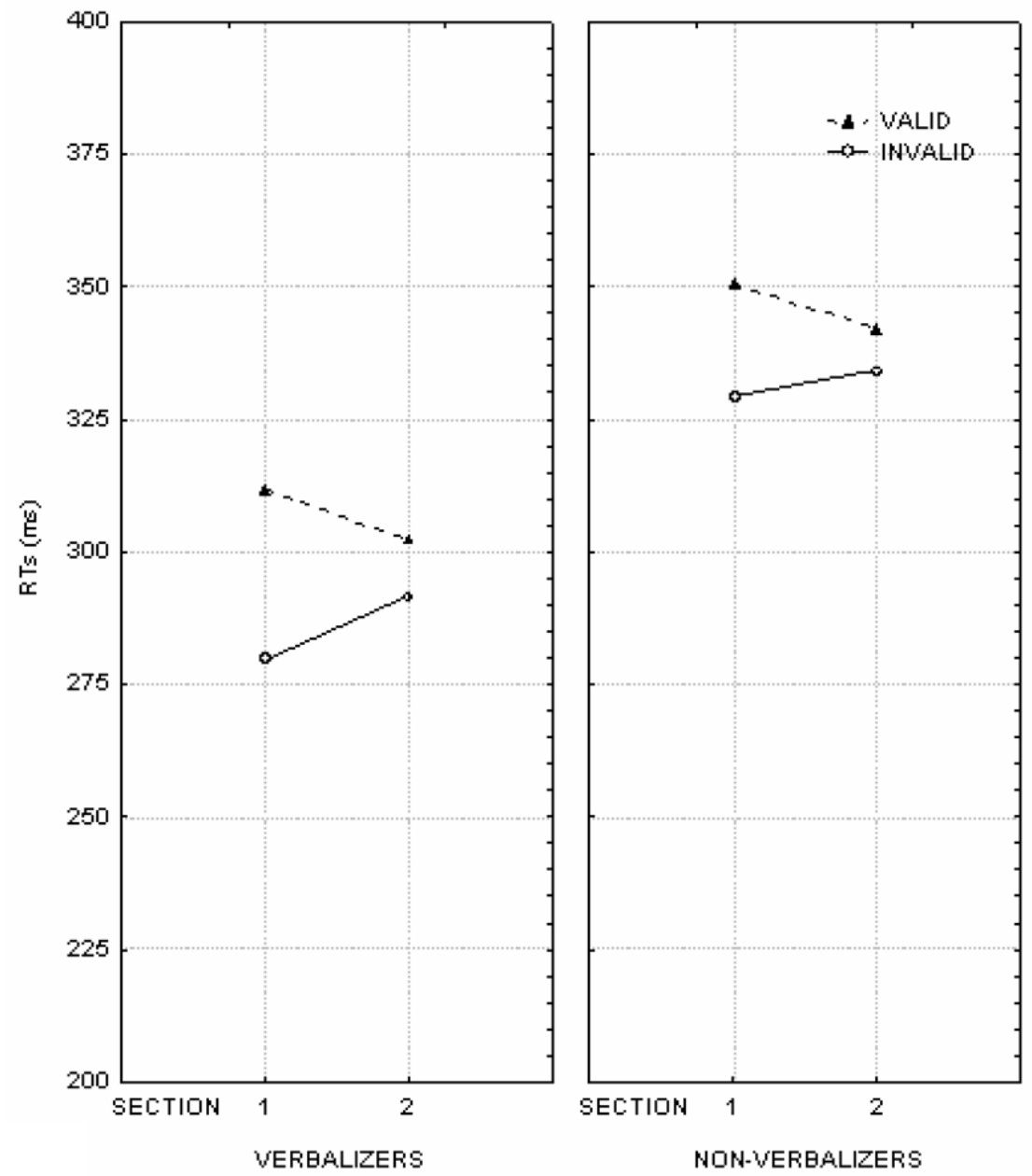
Fig. 2

Fixed effects analysis ( $\leq 50.001$, cluster size $k \geq 5$ ) for complex contrasts $50-80 \%$ vs. 80-50\% across 3 subjects. The results reveal overall stronger activations, if the $50 \%$-condition is subtracted from the $80 \%$ condition (fig. $2 \mathrm{a}$ ) than for the subtraction the other way round (80-50\%, fig. $2 b)$.

\section{Reversed condition (3 subjects)}

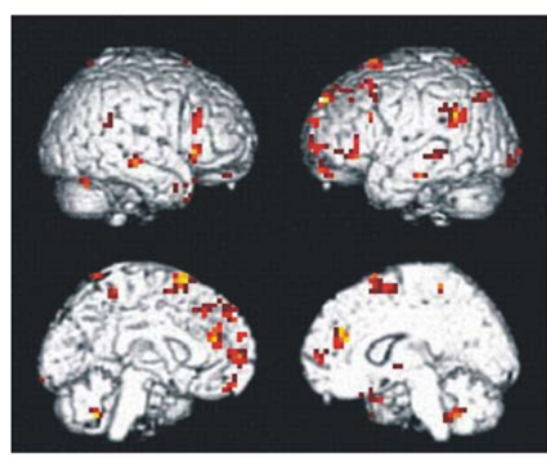

a) $80 \%-50 \%$

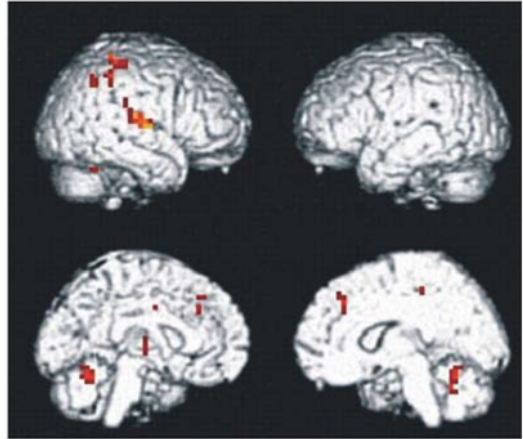

b) $50 \%-80 \%$ 
Fig. 3

Fig. 3a. Verbalizers $80 \%$-valid-condition minus rest, $\mathrm{p} \leq 0.001$, uncorrected, cluster size $\mathrm{k} \geq 5$ Fig. $3 \mathrm{~b}$. Non-verbalizers $80 \%$-valid-condition minus rest, $\mathrm{p} \leq 0.001$, uncorrected, cluster size $\mathrm{k} \geq 5$ Fig. 3c. Verbalizers $>$ non-verbalizers 2 -sample t-test; 80\%-valid-condition, $\mathrm{p} \leq 0.01$, uncorrected, cluster size $\mathrm{k} \geq 5$ Fig. $3 \mathrm{~d}$. Non-verbalizers $>$ verbalizers 2 -sample t-test; $80 \%$-valid-condition, $\mathrm{p} \leq 0.01$, uncorrected, cluster size $\mathrm{k} \geq 5$ Fig. $3 \mathrm{e}$. Verbalizers + non-verbalizers conjunction analysis; 80\%-valid-condition, $\mathrm{p} \leq 0.01$, uncorrected, cluster size k $\geq 5$ Fig. $3 \mathrm{f}$. Verbalizers $>$ non-verbalizers anatomical view of ACC activation; 2-sample t-test; $80 \%$-valid-condition, $\mathrm{p} \leq 0.01$, uncorrected, cluster size $\mathrm{k} \geq 5$

\section{$80 \%$ condition}

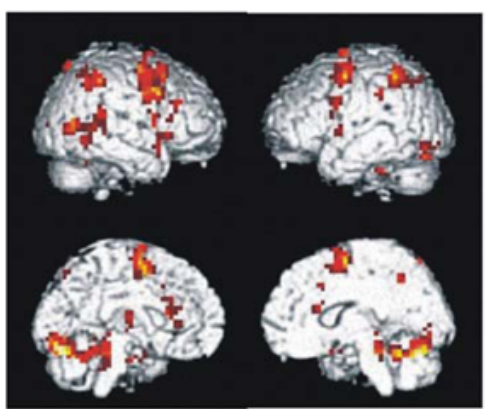

a) Verbalizers

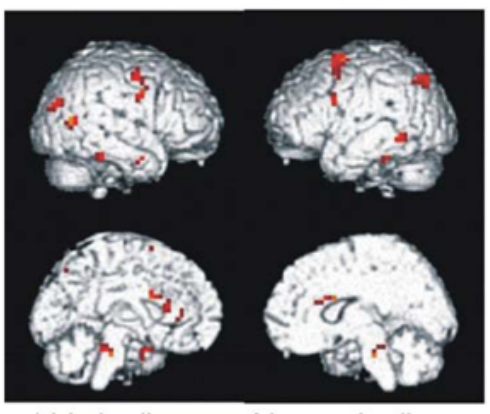

c) Verbalizers > Nonverbalizers

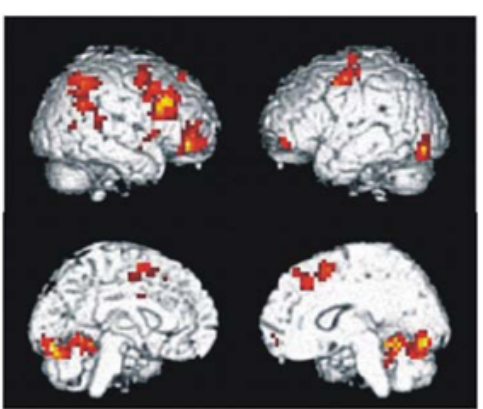

b) Non-Verbalizers

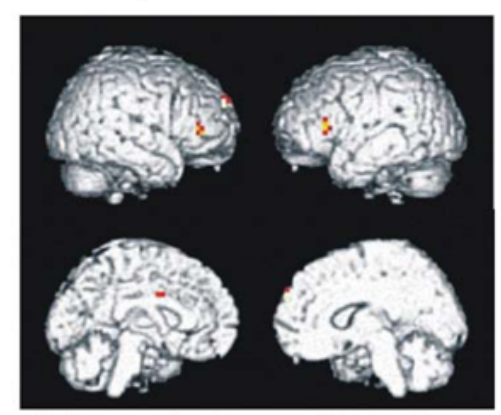

d) Nonverbalizers > Verbalizers

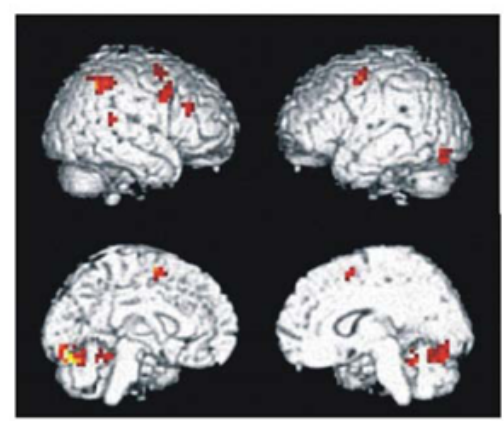

e) Conjunction Verbalizers \& Nonverbalizers

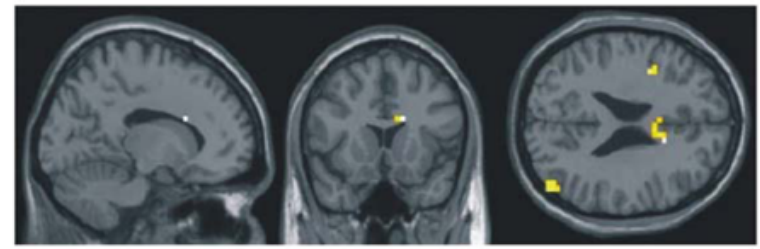

f) Verbalizers > Nonverbalizers ACC Activation 
Fig. 4

Fig. 4a. Verbalizers > non-verbalizers 2 sample t test; $80 \%$ minus $50 \%$ sections, $\mathrm{p} \leq 0.01$, uncorrected, cluster size $\mathrm{k} \geq 5$ Fig. $4 \mathrm{~b}$. Non-verbalizers > verbalizers: 2 sample t-test, $80 \%$ minus $50 \%$ sections, $\mathrm{p} \leq 0.01$, uncorrected, cluster size $\mathrm{k} \geq 5 \mathrm{Fig}$. $4 \mathrm{c}$. Verbalizers $>$ Non-verbalizers anatomical view of ACC activation: 2 sample t-test, $80 \%$ minus $50 \%$ sections, $\mathrm{p} \leq 0.01$, uncorrected, cluster size $\mathrm{k} \geq 5$

\section{$80-50 \%$ condition}

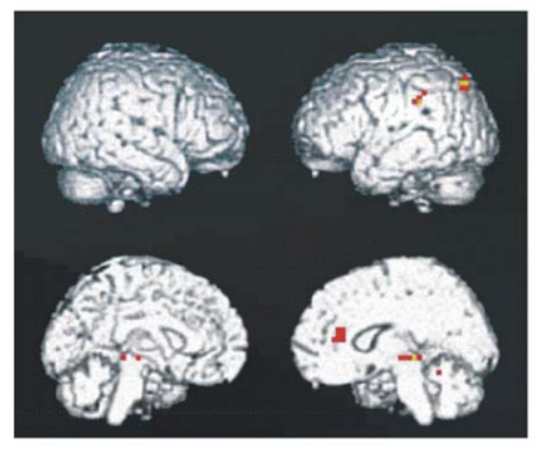

a) Verbalizers > Non-Verbalizers

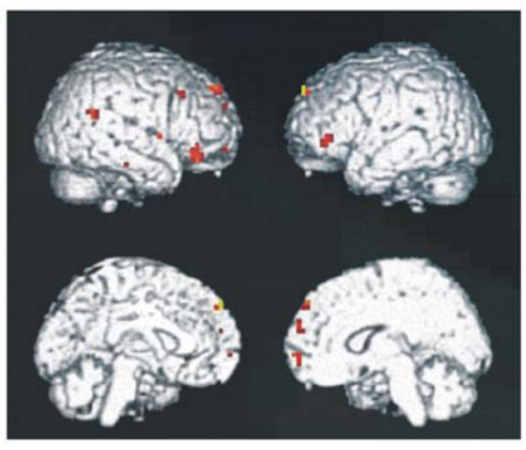

b) Non-Verbalzers > Verbalizers

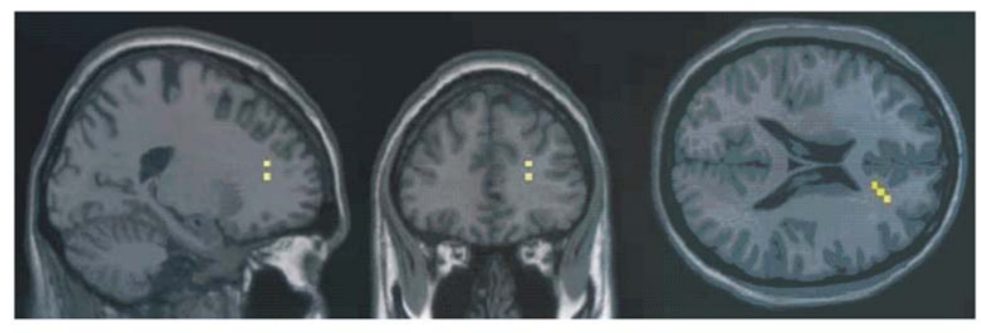

c) Verbalizers > Non-Verbalizers ACC Activation 
Table 1

Mean Response Times (in ms) for Verbalizer and Non-Verbalizer participants (section 1: 50\% valid trials; section 2: $80 \%$ valid trials)

\begin{tabular}{|c|c|c|c|c|c|}
\hline & \multirow[t]{2}{*}{ SOA $(\mathrm{ms})$} & \multicolumn{2}{|l|}{ VERB } & \multicolumn{2}{|c|}{ NON-VERB } \\
\hline & & VALID & INVALID & VALID & INVALID \\
\hline \multirow{3}{*}{$50 \%$ Valid } & 600 & 328 & 291 & 371 & 337 \\
\hline & 80 & 301 & 272 & 341 & 335 \\
\hline & 1000 & 307 & 274 & 341 & 315 \\
\hline \multirow{3}{*}{$80 \%$ Valid } & 60 & 323 & 315 & 363 & 349 \\
\hline & 800 & 287 & 286 & 332 & 330 \\
\hline & 1000 & 294 & 275 & 328 & 323 \\
\hline
\end{tabular}

Table 2

Activation foci for Verbalizers, $80 \%$ condition $(\mathrm{p} \leq 0.001 ; \mathrm{k} \geq 5)$

\begin{tabular}{|c|c|c|c|c|c|c|c|}
\hline & \multirow[t]{2}{*}{ BA approx } & \multirow[t]{2}{*}{ Side } & \multirow[t]{2}{*}{ Cluster size } & \multicolumn{4}{|c|}{ Talairach Coordinates } \\
\hline & & & & $\mathbf{x}$ & $\mathbf{y}$ & $\mathbf{z}$ & z-value \\
\hline \multicolumn{8}{|l|}{ Brain regions } \\
\hline \multicolumn{8}{|l|}{ Parietal cortex } \\
\hline Precuneus & 7 & $\mathrm{~L}$ & 76 & -28 & -44 & 46 & 4.08 \\
\hline Inferior Parietal Lobule & 40 & $\mathrm{~L}$ & 5 & -55 & -33 & 31 & 2.46 \\
\hline Inferior Parietal Lobule & 40 & $\mathrm{R}$ & 86 & 44 & -37 & 42 & 3.71 \\
\hline Superior Parietal Lobule & 7 & $\mathrm{R}$ & 12 & 24 & -67 & 59 & 3.08 \\
\hline \multicolumn{8}{|l|}{ Frontal cortex } \\
\hline Precental Gyrus & 6 & $\mathrm{~L}$ & 197 & -36 & 1 & 29 & 3.75 \\
\hline Precental Gyrus & $9,8,6$ & $\mathrm{R}$ & 180 & 40 & 13 & 36 & 3.74 \\
\hline Medial Frontal Gyrus & 25 & $\mathrm{R}$ & 8 & 12 & 7 & -17 & 3.15 \\
\hline Anterior Cingulate & 24 & $\mathrm{R}$ & 8 & 12 & 17 & 21 & 3.03 \\
\hline Cingulate Gyrus & 32 & $\mathrm{R}$ & 5 & 12 & 21 & 36 & 2.88 \\
\hline \multicolumn{8}{|l|}{ Temporal Cortex } \\
\hline Inferior Temporal Gyrus & 37 & $\mathrm{R}$ & 41 & 55 & -55 & -4 & 3.05 \\
\hline \multicolumn{8}{|l|}{ Occipital cortex } \\
\hline Fusiform Gyrus & 37 & $\mathrm{R}$ & 5 & 28 & -47 & -11 & 2.72 \\
\hline \multicolumn{8}{|l|}{ Subcortical areas } \\
\hline Thalamus_Ventral Lateral Nucleus & * & $\mathrm{L}$ & 13 & -16 & -11 & 12 & 3.44 \\
\hline Lentiform Nucleus, Putamen & * & $\mathrm{L}$ & 6 & -28 & 4 & -7 & 2.84 \\
\hline Caudate, Caudate Body & * & $\mathrm{L}$ & 31 & -16 & 20 & 14 & 2.90 \\
\hline
\end{tabular}


Table 3

Activation foci for Non-Verbalizers, $80 \%$ valid condition ( $\mathrm{p} \leq 0.001 ; \mathrm{k} \geq 5$ )

\begin{tabular}{|c|c|c|c|c|c|c|c|}
\hline & \multirow[t]{2}{*}{ BA approx } & \multirow[t]{2}{*}{ Side } & \multirow[t]{2}{*}{ Cluster Size } & \multicolumn{4}{|c|}{ Talairach Coordinates } \\
\hline & & & & $\mathbf{x}$ & $\mathbf{y}$ & $\mathbf{z}$ & z-value \\
\hline \multicolumn{8}{|l|}{ Brain regions } \\
\hline \multicolumn{8}{|l|}{ Parietal cortex } \\
\hline Postcentral Gyrus & 3,1 & $\mathrm{~L}$ & 41 & -51 & -9 & 52 & 3.66 \\
\hline Superior Parietal Lobule & 7 & $\mathrm{R}$ & 148 & 32 & -56 & 40 & 3.70 \\
\hline \multicolumn{8}{|l|}{ Frontal cortex } \\
\hline Superior Frontal Gyrus & 6,8 & $\mathrm{R}$ & 75 & 8 & 14 & 51 & 3.46 \\
\hline Middle Frontal Gyrus & 11,10 & $\mathrm{R}$ & 60 & 44 & 42 & -9 & 4.23 \\
\hline Middle Frontal Gyrus & $9,8,46,6$ & $\mathrm{R}$ & 217 & 48 & 37 & 31 & 3.54 \\
\hline Superior Frontal Gyrus & 6 & $\mathrm{~L}$ & 12 & -28 & -8 & 67 & 3.01 \\
\hline Middle Frontal Gyrus & 47,10 & $\mathrm{~L}$ & 11 & -8 & 46 & -9 & 2.72 \\
\hline Cingulate Gyrus & 24 & $\mathrm{~L}$ & 31 & -20 & -2 & 44 & 3.11 \\
\hline \multicolumn{8}{|l|}{ Temporal Cortex } \\
\hline Claustrum & * & $\mathrm{R}$ & 23 & 36 & 4 & -0 & 3.21 \\
\hline Middle Temporal Gyrus & 39 & $\mathrm{R}$ & 6 & 44 & -58 & 10 & 3.00 \\
\hline \multicolumn{8}{|l|}{ Occipital cortex } \\
\hline Fusiform Gyrus & 37 & $\mathrm{R}$ & 5 & 28 & -47 & -11 & 2.72 \\
\hline \multicolumn{8}{|l|}{ Subcortical areas } \\
\hline Caudate, Caudate Tail & * & $\mathrm{R}$ & 8 & 36 & -39 & 2 & 2.59 \\
\hline
\end{tabular}


Table 4

Activation foci for Verbalizers > Non-Verbalizers, $80 \%$ valid (2-sample t-test, total $n=22, p \leq 0.01 ; k \geq 5$ )

\begin{tabular}{|c|c|c|c|c|c|c|c|}
\hline & \multirow[t]{2}{*}{ BA approx } & \multirow[t]{2}{*}{ Side } & \multirow[t]{2}{*}{ Cluster size } & \multicolumn{4}{|c|}{ Talairach Coordinates } \\
\hline & & & & $\mathbf{x}$ & $\mathbf{y}$ & $\mathbf{z}$ & z-value \\
\hline \multicolumn{8}{|l|}{ Brain regions } \\
\hline \multicolumn{8}{|l|}{ Parietal cortex } \\
\hline Superior Parietal Lobule & 7 & $\mathrm{~L}$ & 22 & -24 & -64 & 44 & 3,24 \\
\hline \multicolumn{8}{|l|}{ Frontal cortex } \\
\hline Anterior Cingulate & $24,32,33$ & $\mathrm{R}$ & 11 & 12 & 17 & 21 & 3,19 \\
\hline Anterior Cingulate & $24,32,33$ & $\mathrm{~L}$ & 7 & -4 & 9 & 25 & 2,90 \\
\hline Precentral Gyrus & 4,6 & $\mathrm{R}$ & 19 & 55 & -1 & 48 & 3,01 \\
\hline Inferior Frontal Gyrus & 9 & $\mathrm{~L}$ & 11 & -40 & 5 & 22 & 2,89 \\
\hline \multicolumn{8}{|l|}{ Temporal Cortex } \\
\hline Middle Temporal Gyrus & $19,20,39$ & $\mathrm{R}$ & 12 & 55 & -61 & 14 & 3,25 \\
\hline Middle Temporal Gyrus & 6 & $\mathrm{~L}$ & 26 & -28 & 7 & 59 & 3,25 \\
\hline Middle Temporal Gyrus & 21,37 & $\mathrm{~L}$ & 8 & -55 & -51 & -4 & 3,00 \\
\hline Middle Temporal Gyrus & 39 & $\mathrm{R}$ & 10 & 48 & -72 & 29 & 2,82 \\
\hline \multicolumn{8}{|l|}{ Occipital cortex } \\
\hline Fusiform Gyrus & $20,36,37$ & $\mathrm{R}$ & 5 & 44 & -5 & -20 & 3,01 \\
\hline Fusiform Gyrus & 20,37 & $\mathrm{R}$ & 6 & 51 & -36 & -18 & 2,74 \\
\hline Fusiform Gyrus & $20,36,37$ & $\mathrm{~L}$ & 8 & -40 & -36 & -22 & 2,80 \\
\hline \multicolumn{8}{|l|}{ Subcortical areas } \\
\hline Uncus, Amygdala & 28 & $\mathrm{~L}$ & 7 & -20 & -1 & -23 & 2,65 \\
\hline
\end{tabular}

\section{Table 5}

Activation foci for Non-Verbalizers $>$ Verbalizers, $80 \%$ valid (2-sample t-test, total $n=22, p \leq 0.01 ; k \geq 5$ )

\begin{tabular}{|c|c|c|c|c|c|c|c|}
\hline & \multirow[t]{2}{*}{ BA approx } & \multirow[t]{2}{*}{ Side } & \multirow[t]{2}{*}{ Cluster size } & \multicolumn{4}{|c|}{ Talairach Coordinates } \\
\hline & & & & $\mathbf{x}$ & $\mathbf{y}$ & $\mathbf{z}$ & z-value \\
\hline \multicolumn{8}{|l|}{ Frontal cortex } \\
\hline Inferior Frontal Gyrus & 46 & $\mathrm{R}$ & 7 & 44 & 35 & 6 & 2.90 \\
\hline Inferior Frontal Gyrus & 9 & $\mathrm{R}$ & 8 & 16 & 60 & 26 & 2.80 \\
\hline Inferior Frontal Gyrus & 13 & $\mathrm{~L}$ & 7 & -40 & 24 & 6 & 2.95 \\
\hline
\end{tabular}


Table 6

Activation foci for the conjunction analysis Verbalizers \& Non-Verbalizers, $80 \%$ valid (2-sample t-test, total $n=22, p \leq 0.01 ; k \geq 5$ )

\begin{tabular}{|c|c|c|c|c|c|c|c|}
\hline & \multirow[t]{2}{*}{ BA approx } & \multirow[t]{2}{*}{ Side } & \multirow[t]{2}{*}{ Cluster size } & \multicolumn{4}{|c|}{ Talairach Coordinates } \\
\hline & & & & $\mathbf{x}$ & $\mathbf{y}$ & $\mathbf{z}$ & z-value \\
\hline \multicolumn{8}{|l|}{ Brain regions } \\
\hline \multicolumn{8}{|l|}{ Parietal cortex } \\
\hline Inferior Parietal Lobule & 40 & $\mathrm{R}$ & 46 & 44 & -37 & 46 & 3.01 \\
\hline \multicolumn{8}{|l|}{ Frontal cortex } \\
\hline Middle Frontal Gyrus & 6 & $\mathrm{~L}$ & 12 & -40 & -1 & 48 & 3.11 \\
\hline Inferior Frontal Gyrus & 9 & $\mathrm{R}$ & 40 & 48 & 5 & 29 & 2.95 \\
\hline Middle Frontal Gyrus & 6 & $\mathrm{R}$ & 7 & 40 & 3 & 51 & 2.67 \\
\hline Superior Frontal Gyrus & 6 & $\mathrm{~L}$ & 19 & 0 & 7 & 55 & 2.60 \\
\hline \multicolumn{8}{|l|}{ Temporal cortex } \\
\hline Superior Temporal Gyrus & 22 & $\mathrm{R}$ & 6 & 59 & -38 & 17 & 2.58 \\
\hline
\end{tabular}

Table 7

Activation foci for Verbalizers > Non-Verbalizers, $80 \%$ valid minus $50 \%$ valid (2-sample t-test, total $n=22, p \leq 0.01 ; k \geq 5)$

\begin{tabular}{|c|c|c|c|c|c|c|c|}
\hline & \multirow[t]{2}{*}{ BA approx } & \multirow[t]{2}{*}{ Side } & \multirow[t]{2}{*}{ Cluster size } & \multicolumn{4}{|c|}{ Talairach Coordinates } \\
\hline & & & & $\mathbf{x}$ & $\mathbf{y}$ & $\mathbf{z}$ & z-value \\
\hline \multicolumn{8}{|l|}{ Brain regions } \\
\hline \multicolumn{8}{|l|}{ Parietal cortex } \\
\hline Superior Parietal Lobule & 7 & $\mathrm{~L}$ & 10 & -32 & -71 & 48 & 3.06 \\
\hline Inferior Parietal Lobule & 40 & $\mathrm{~L}$ & 5 & -55 & -33 & 31 & 2.46 \\
\hline \multicolumn{8}{|l|}{ Frontal cortex } \\
\hline Anterior Cingulate Gyrus & 32 & $\mathrm{R}$ & 8 & 20 & 36 & 17 & 2.67 \\
\hline \multicolumn{8}{|l|}{ Occipital cortex } \\
\hline Fusiform Gyrus & 37 & $\mathrm{R}$ & 5 & 28 & -47 & -11 & 2.72 \\
\hline \multicolumn{8}{|l|}{ Subcortical areas } \\
\hline Brainstem & & $\mathrm{R}$ & 7 & 8 & -20 & 2 & 2.75 \\
\hline
\end{tabular}


Table 8

Activation foci for Non-Verbalizers $>$ Verbalizers, $80 \%$ valid minus $50 \%$ valid (2-sample t-test, total $n=22, p=0.01 ; k \geq 5$ )

\begin{tabular}{|c|c|c|c|c|c|c|c|}
\hline & \multirow[t]{2}{*}{ BA approx } & \multirow[t]{2}{*}{ Side } & \multirow[t]{2}{*}{ Cluster size } & \multicolumn{4}{|c|}{ Talairach Coordinates } \\
\hline & & & & $\mathbf{x}$ & $\mathbf{y}$ & $\mathbf{z}$ & z-value \\
\hline \multicolumn{8}{|l|}{ Brain regions } \\
\hline \multicolumn{8}{|l|}{ Parietal cortex } \\
\hline Inferior Parietal Lobule & 39 & $\mathrm{R}$ & 5 & 55 & -49 & 21 & 3.27 \\
\hline \multicolumn{8}{|l|}{ Frontal cortex } \\
\hline Inferior frontal Gyrus & 47 & $\mathrm{R}$ & 8 & 51 & 30 & -12 & 3.40 \\
\hline Middle frontal Gyrus & 9 & $\mathrm{R}$ & 5 & 36 & 21 & 32 & 2.97 \\
\hline \multirow[t]{2}{*}{ Superior frontal Gyrus } & 10 & $\mathrm{R}$ & 6 & 8 & 58 & -6 & 2.85 \\
\hline & 9 & $\mathrm{~L}$ & 7 & -4 & 56 & 34 & 3.73 \\
\hline \multicolumn{8}{|l|}{ Temporal Cortex } \\
\hline Inferior Temporal Gyrus & 20 & $\mathrm{R}$ & 5 & 51 & -24 & -16 & 2.45 \\
\hline Insula & 13 & $\mathrm{R}$ & 9 & 44 & 4 & 3 & 2.57 \\
\hline
\end{tabular}

